\title{
Mersin Bölgesinde Yaşayan Yüksek Riskli Myelodisplastik Sendrom Hastalarında Kronik Hastalık Varlığının Sağ Kalım Üzerine Etkisi*
}

\author{
The Effect of Chronic Disease on Survival in High-risk Myelodysplastic Syndrome Patients Living in Mersin \\ Mehmet Ali Uçari \\ iDr. Öğr. Üyesi, Mersin Üniversitesi Tıp Fakültesi Hematoloji B.D. \\ https://orcid.org/0000-0002-6041-7364
}

öz

\begin{abstract}
Amaç: Myelodisplastik sendrom hematopoetik sistemin klonal kök hücre hastalığıdır. Myelodisplastik sendrom, 65 yaş üzerinde erkeklerde daha sık görülen bir hastalıktır. Prognoz tayininde sitogenetik inceleme, kemik iliğindeki blast sayısı ve sitopeninin derecesinin eklenmesi ile Uluslarası Prognoz Puanlama Sistemi (IPSS) kullanılır. Yüksek riskli myelodisplastik sendrom hastalarında kronik hastalıkların sağ kalım üzerine etkisi ve prognostik değerini tespit etmek üzere bu çalışma planlandı.
\end{abstract}

Yöntem: 2011 ocak ve 2019 ocak yılları arasında Mersin Üniversitesi Tıp Fakültesi Hematoloji polikliniğinde MDS tanılı hastalar retrospektif olarak değerlendirildi. 18-96 yaş arası, kronik hastalık varlığı tanı anında veya öncesinde mevcut olan, kemik iliği biyopsisi ile MDS tanısı konan 124 hasta çalışmaya alındı. Kategorik değişkenler sayı ve yüzde olarak belirtildi. Mortalite ile ilişkili bulgular univariable Cox regression analiz ile değerlendirildi.

Bulgular: Hastaların ortalama yaşı 67 yıldı. Kardiyak hastalık, serebrovasküler hastalık, kanser ve kronik obstruktif akciğer hastalığı mortalite riskini arttıran olası risk faktörleri olarak saptandı. Yaşın 1 yıl artması 1,03 kat mortalite riskini arttırdığı saptandı. Kardiyak hastalığı olanlar olmayanlara kıyasla 1,60 kat mortalite riskine sahipti. KOAH olanlar olmayanlara kıyasla 1,78 kat mortalite riskini sahipti.

Sonuç: İleri yaş, kardiyak hastalık, serebrovasküler hastalık, kanser ve kronik obstruktif akciğer hastalığı mortalite riskini arttıran olası risk faktörleri olarak saptandı. Bu çalışma MDS üzerine Mersin bölgesinden yapılmış tek merkezli en fazla hasta sayısına sahip olan ilk çalışma olması nedeni ile önemlidir. Bununla birlikte elde ettiğimiz bu verilerin Mersin'de yaşayan MDS hastalarında kronik hastalık varlığının mortaliteye etkisi ve en uygun tedavi seçeneklerini belirlemeye ışık tutacağını düşünmekteyiz.

Anahtar Kelimeler: Myelodisplastik Sendrom, Kronik Hastalık, Prognoz.

\section{ABSTRACT}

Aim: Myelodysplastic syndrome is a clonal stem cell disease of the hematopoietic system. Myelodysplastic syndrome is a more common disease in men over 65 years of age. Prognosis is determined by the addition of cytogenetic examination, bone marrow blast number and degree of cytopenia and the International Prognosis Scoring System (IPSS). This study was planned to determine the effect of chronic diseases on survival and prognostic value in patients with high risk myelodysplastic syndrome.

Method: Between January 2011 and January 2019, patients diagnosed with MDS in the Hematology outpatient clinic of Mersin University Medical Faculty were evaluated retrospectively. A total of 124 patients aged 18-96 years, who were present before or at the time of diagnosis of chronic disease, were diagnosed as MDS by bone marrow biopsy. Categorical variables were expressed as numbers and percentages. Mortality-related findings were evaluated by univariable Cox regression analysis.

Results: The mean age of the patients was 67 years. Cardiac disease, cerebrovascular disease, cancer and chronic obstructive pulmonary disease were identified as possible risk factors increasing the mortality risk. It was found that increasing age 1 year increased the risk of mortality 1.03 times. Those with cardiac disease had a 1.60 -fold mortality risk compared to those without. Those with COPD had a 1.78 -fold mortality risk compared to those without.

Conclusion: Advanced age, cardiac disease, cerebrovascular disease, cancer and chronic obstructive pulmonary disease were identified as possible risk factors that increased mortality. This study is important because it is the first study with the highest number of patients with single center in Mersin region on MDS. However, we think that these data will shed light on the effect of the presence of chronic disease on mortality and the most appropriate treatment options in MDS patients living in Mersin.

Key Words: Myelodysplastic syndrome, chronic disease, prognosis.

*Lokman Hekim Dergisi, 2019; 9 (3): 349-356

DOI: $10.31020 /$ mutftd.593357

e-ISSN: $1309-8004$

Geliş Tarihi-Received: 17 Temmuz 2019; Kabul Tarihi - Accepted: 30 Ağustos 2019

Iletişim - Correspondence Author: Mehmet Ali Uçar <mucardr@hotmail.com> 


\section{Giriş}

Myelodisplastik sendrom (MDS) hematopoetik sistemin klonal, edinilmiş kök hücre hastalığıdır. Kemik iliğinde displaziler ile birlikte, kemik iliği sellüleritesinin artmış olduğu ve kemik iliğinde myeloblast artışına da neden olabilen, akut myeloblastik (AML) dönüşüm riskine sahip bir hastalıktır. MDS, de novo gelişebileceği gibi daha önce alınmış kemoterapi ve radyoterapilere sekonder de gelişebilir. Kemik iliğinde eritrositik, megakaryositik ve granülositik serilerin her üçü de etkilenebilir. MDS, erkeklerde daha sık görülen, primer olarak 65 yaş üzerinde ortaya çıkabilen, yaş arttıkça görülme insidansın da artışa neden olabilen bir hastalıktır. ${ }^{1,2}$

Myelodisplastik sendrom hastalarının büyük bir kısmında etyoloji ortaya konamaz. Kemoterapi ve radyoterapi dışında kimyasal ajanlara maruziyet, viral enfeksiyonlar, tarım ilaçları gibi bazı sitotoksik ajanlar, kemik iliğinde delesyonlara, kompleks karyotipik bozukluk ve kromozomal anormalliklere neden olarak MDS gelişimine neden olabilirler. Hematopoetik kök hücrede kromozomal yapı bozukluğu sonucu malign bir klon ortaya çıkar, bu klonal hastalık yanında blastik hücre artışı ve infiltrasyonu sonucu lösemiye transformasyon gelişir. $^{3,4}$

Prognoz tayininde sadece hemogram ve kemik iliği değerlendirmelerinin yanı sıra sitogenetiğin de anlamlı derecede etkili olduğu kanıtlanmıştır. Bunun üzerine Prognostik ölçümlere sitogenetik inceleme, kemik iliğindeki blast sayısı ve sitopeninin derecesinin eklenmesi ile Uluslarası Prognoz Puanlama Sistemi (IPSS) geliştirilmiştir. IPSS skorlama sistemine sitogenetik birtakım belirteçlerin eklenmesi daha iyi bir prognositik göstergeye sahip revise IPSS (R-IPSS) elde edilir. Yukarda tanımlanmış prognositik skorlama sistemleri dışında, eşlik eden kronik böbrek, kalp, akciğer ve karaciğer hastalıkları mortaliteye etki eden diğer faktörler olarak ön plana çıkmaktadır. ${ }^{5-7}$

Ileri yaş, hem hastaların daha yoğun tedavi almalarını sınırlayarak yüksek riskli hastaların hayatta kalmasını da etkileyeceği gibi hem de yaşla birlikte artan kronik hastalıklar morbidite ve mortalite riskini arttırmaktadır. Bundan dolayı ileri yaş, yüksek riskli MDS hastalarının sağ kalımı üzerine olumsuz bir etkiye sahiptir. ${ }^{8}$ Sadece yaşın ileri olması değil aynı zamanda eşlik eden komorbideteler, yaşam performansın düşük olması ile ilgili faktörler MDS'li hastalarda sağkalımı etkileyebilir. Komorbiditelerin prognostik değeri son zamanlarda allojenik kök hücre transplantasyonu yapılan hastalarda, AML'li yaşlı hastalarda, lenfoproliferatif hastalıklarda gösterilmiştir. Ancak şimdiye kadar, MDS'de kronik hastalıklar ve komorbiditeler üzerine ülkemizde çok az çalışma yayınlanmıştır. Yüksek riskli MDS hastalarında kronik hastalıkların sağ kalım üzerine etkisi ve prognostik değerini tespit etmek üzere bu çalışma planlandı. ${ }^{9,10}$

\section{MATERYAL VE METOD}

Ocak 2011 ve ocak 2019 yılları arasında Mersin Üniversitesi Tıp Fakültesi Hematoloji Bilim Dalı'nda MDS tanılı hastalar retrospektif olarak hastane kayıtlarından edinilen bilgilerle dosya verileri ele alınarak değerlendirildi. Çalışmamıza yaşı 18 'in üstü olan toplam 124 hasta alındı. Hastaların kan sayımı ve biyokimyasal tetkikleri Merkez Biokimya laboratuarında rutin yöntemler kullanılarak yapılmıştı. Periferik kan yaymaları ve kemik iliği biyopsi, kemik iliği aspirasyonları Hematoloji laboratuarında, kemik iliği biyopsi materyali ise Mersin Üniversitesi Tıp Fakültesi Patolojik Anabilim Dalı Laboratuarında, kemik iliği sitogenetik analizi iste konvansiyonel sitogenetik inceleme ile Mersin Üniversitesi Tıp Fakültesi Tıbbı Genetik Bilim Dalı́nda değerlendirilmiştir. Çalışmaya dahil edilme kriterleri olarak; Mersin Üniversitesi Tıp Fakültesi Hematoloji polikliniğinde 01.01.2010 ile 01.01.2019 tarihleri arasında myelodisplastik sendrom tanısı alanlar, tanı anında veya öncesinde kronik hastalığı olanlar, kemik iliği biyopsi ile MDS tanısı konmuş olanlar, MDS alt tiplerinden yüksek riske sahip MDS blast artışı-1, MDS blast artışı-2 ve MDS çoklu seride displasizisi alt tipine sahip hastaların çalışmaya alınması planlandı. Dışlanma kriterleri olarak; 18 yaş altı ve 96 yaş üzeri 01.01.2010 öncesi ile 01.01.2019 sonrası MDS tanısı alan hastalar, kronik hastalık varlığının tanıdan sonra ortaya çıkması, Kemik iliği biyopsisi yapılmamış olanlar veya yetersiz olanlar, MDS alt tiplerinden yüksek riske sahip olan MDS blast artışı-1, MDS blast artışı-2 ve MDS çoklu seride displasizi dışında alt tipe sahip MDS hastalarının çalışmaya alınmaması planlandı. 
2016 yılında WHO tarafından yeni sınıflama tanımlanmış olup, Bu sınıflamada;

1. Tek seri displazisi, (MD-SLD),

2. MDS Ring sideroblastlar ile birlikte MDS (MDS-RS)

3. Çok seride displazi ile beraber olan (MDS-MLD)

4. Kemik iliğinde blast artışı ile giden \% 5-9 blast olan (MDS-EB-1),

5. Kemik iliğinde blast artışı ile giden \% 10-19 blast olan (MDS-EB-2),

6. Sinıflandırılamayan MDS (MDS-U)

7. İzole $5 q$ delesyonu ile beraber MDS

8. MDS Geçici antite: Çocukluk çağının refrakter sitopenisi Germline eğilimli myeloid neoplazmlar Refrakter anemi/sitopeni yerine displazi ifadesi kullanılmaktadır. ${ }^{10}$

Çalışmamızda hastalar prognostik skorlama sistemlerinden olan IPSS ve R-IPSS'e göre gruplandırıldı (Tablo 1). Mevcut skorlama sistemlerinde gruplara ayrılan hastalarımız; ölen hastalar tanı tarihinden ölüm tarihine kadar geçen süre (ay) ve yaşayan hastalar için tanı tarihinden en son 12.07.2019 tarihine kadar olan median yaşam süreleri belirlendi. Çalışmamız Helsinki Deklerasyon prensiplerine sadık kalınarak, Mersin Üniversitesi Tıp Fakültesi Bilimsel Etik Kuruluna yapılan başvuru sonucunun değerlendirilmesi sonucu uygun görülüp onay verilmesi üzerine yapılmıştır. (Etik kurul tarih: 10.07.2019, Sayı no: 2019-300)

Tablo 1. Revize Uluslarası Prognostik Puanlama Sistemi (R-IPSS), Uluslarası Prognostik Puanlama Sistemi (IPSS)

\begin{tabular}{|c|c|c|c|c|c|c|c|}
\hline \multicolumn{8}{|c|}{ Revize Uluslarası Prognostik Puanlama Sistemi (R-IPSS) } \\
\hline Prognostik değişken/skor & 0 & 0,5 & 1 & 1,5 & 2 & 3 & 4 \\
\hline Sitogenetik (x) & Çok iyi & - & İyi & - & Orta & Kötü & Çok kötü \\
\hline Blast (\%) & $\leq 2$ & - & $>2-<5$ & - & $5-10$ & $>10$ & - \\
\hline $\mathrm{Hb}$ & $\geq 10$ & - & $8-<10$ & $<8$ & -- & - & - \\
\hline Trombosit & $\geq 100$ & $50-<100$ & $<50$ & - & - & - & - \\
\hline Mutlak Nötrofil Sayısı & $>0,8$ & $\leq 0,8$ & - & - & - & - & \\
\hline \multicolumn{8}{|c|}{ Uluslarası Prognostik Puanlama Sistemi (IPSS) } \\
\hline Puan değeri & 0 & 0,5 & 1 & 1,5 & 2 & & \\
\hline Kemik iliği blast (\%) & $<5$ & $5-10$ & & $1-20$ & $21-30$ & & \\
\hline Karyotip (*) & İyi & Orta & Kötü & & & & \\
\hline Sitopeni $(* *)$ & $0-1$ & $2-3$ & & & & & \\
\hline
\end{tabular}

(*) lyyi: Normal, $-Y$, del (5q), del (20q), Kötü: Kompleks ( $\geq 3$ anomali) veya kromozom 7 anomalileri. Orta: Diğer anomaliler. (**) Hemoglobin $<10 \mathrm{gr} / \mathrm{dL}$, mutlak nötrofil sayısı: $<1.8 \times 10^{9} / \mathrm{L}$, trombosit<100 x 10\%/L. Greenberg PL, Tuechler H, Schanz J et al. Revised International Prognostic Scoring System for myelodysplastic syndromes. Blood 2012; 120: 2454-2465

\section{İstatistiksel Analiz}

İstatistiksel değerlendirme bilgisayar ortamında yapıldı. Verilerin normal dağılımının değerlendirilmesinde

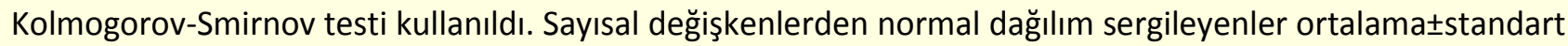
sapma olarak, normal dağılım sergilemeyenler ortanca (min-max) olarak gösterildi. Kategorik değişkenlerin tanımlamasında sayı ve yüzde ifadeleri kullanıldı. Mortalite ile ilişkili bulgular univariable Cox regression analiz ile değerlendirildi ve anlamlı bulunan olası risk faktörleri multivariable cox regression modeline dahil edilerek bağımsız risk faktörleri saptandı. Sağkalım grafikleri kaplan-meier analizi ile yapıldı.

İstatistiksel analizlerde $p<0.05$ değeri anlamlı olarak kabul edildi. 


\section{BULGULAR}

Araştırma popülasyonu yüksek riskli myelodisplastik sendrom tanısı alan 124 hastadan oluştu. Hastaların ortalama yaşı $67 \pm 12,2$ yıl, erkek oranı $\% 55,6$ ve kadın oranı $\% 44,4$ olarak saptandı. Yüksek riskli MDS hastalarının \%79,8'inde hipertansiyon (HT), \%61,3'ünde kardiyak hastalık, \%33,1'inde diabetes mellitus (DM), \%21,8'inde serebrovasküler hastalık (SVH), \%20,2'sinde kanser, \%17,7'sinde kronik obstruktif akciğer hastalığı (KOAH), \%13,7'sinde renal hastalık, \%8,1'inde tiroid hastalık, \%3,2'sinde kollojen doku hastalığı ve \%2,4'ünde karaciğer hastalığı saptandı. Kronik hastalıkların ölen ve sağ kalan hastalardaki dağılımları (Şekil 1)'de gösterildi. Kardiyak hastalık, SVH, kanser ve KOAH mortalite riskini arttıran olası risk faktörleri olarak saptandı (Tablo 2).

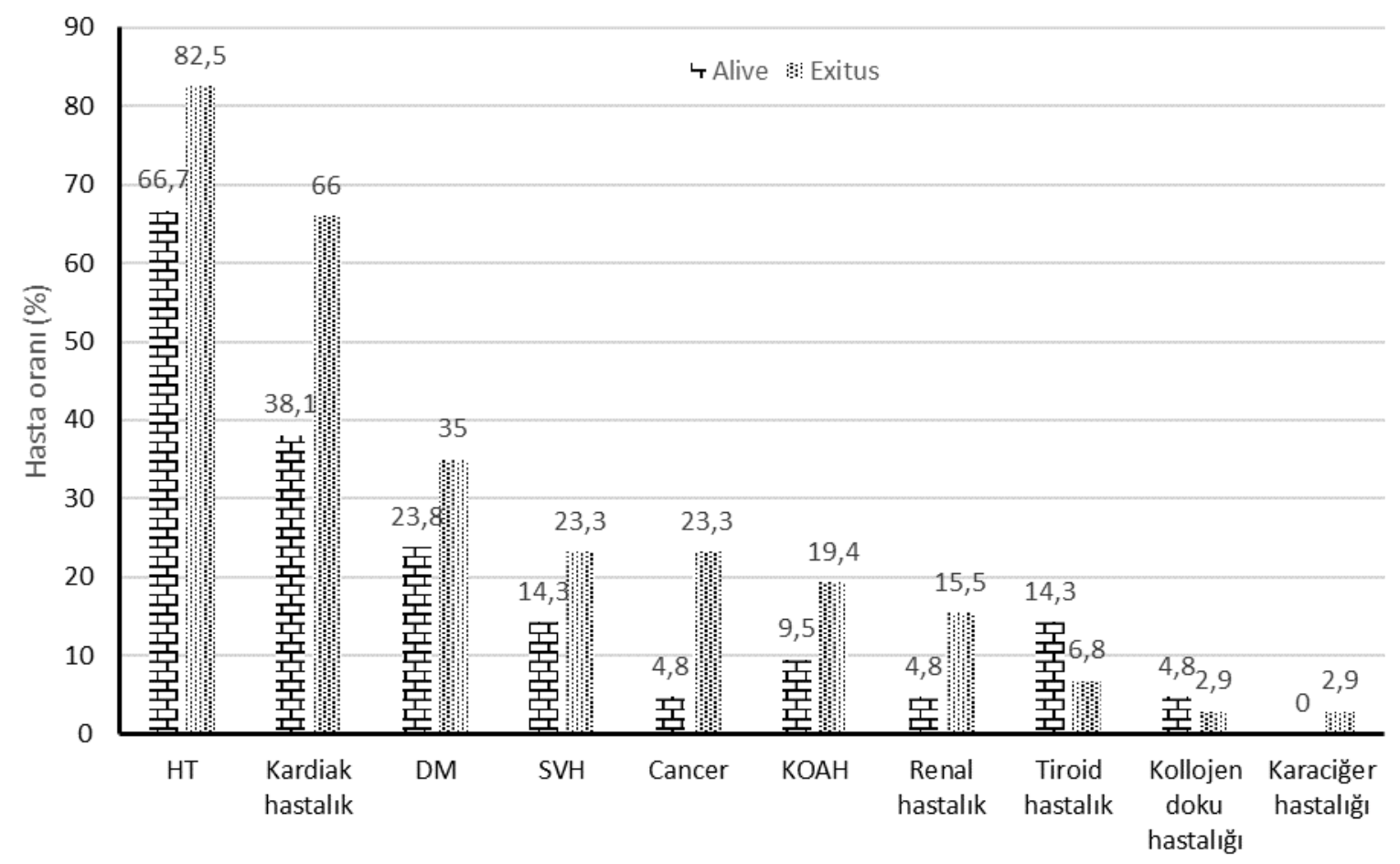

Şekil 1. Kronik hastalıkların ölen ve sağkalan hastalarda dağılımı

Yüksek riskli MDS hastalarının takipleri süresince \%56,5'inde AML belirlendi. Hastaların \%21'inde MDS-MLD, $\% 50,8^{\prime}$ inde MDS-EB1 ve \%28,2'sinde MDS-EB2 tipi belirlendi. Hastaların \%19,4'ü eritropoetin, \%55,6'sı azasitidin, \%42,7'si desitabin, \%4,8'i immün modülatör ajan (imid: Thalidomid veya lenalidomid), \%8,9'u immünsüpresif tedavi aldığı belirlendi. Hastaların IPSS skorları 0,5-3 aralığında olup ortancası 1 idi ve $\% 24,2$ 'sinde düşük, $\% 47,6$ 'sında orta-1 ve $\% 28,2$ 'sinde orta-2 olarak belirlendi. R-IPSS skor aralığı 3,5-8,5 aralığında olup ortancası 4,5 idi ve hastaların $\% 51,6$ 'sı orta, $\% 37,9^{\prime}$ u yüksek ve $\% 10,5^{\prime} i$ çok yüksekti. MDSEB2, artan IPSS skor ve artan R-IPSS skorları mortalite ile anlamlı ilişki gösterdi (Tablo 3). 
Tablo 2. Demografik özellikler

\begin{tabular}{|c|c|c|c|c|c|c|}
\hline \multirow[b]{2}{*}{ Değişkenler } & \multirow{2}{*}{$\begin{array}{c}\text { Total } \\
\text { population } \\
\mathrm{n}=124\end{array}$} & \multicolumn{2}{|c|}{ Survival } & \multicolumn{3}{|c|}{ Univariable Regression } \\
\hline & & $\begin{array}{c}\text { Sağ } \\
n=21\end{array}$ & $\begin{array}{l}\text { Exitus } \\
n=103\end{array}$ & HR & $95 \% \mathrm{Cl}$ & $\mathbf{p}$ \\
\hline Yaş & $67 \pm 12,2$ & $62 \pm 11,5$ & $68 \pm 12,1$ & 1,03 & $1,01-1,05$ & $0,005^{*}$ \\
\hline \multicolumn{7}{|l|}{ Cinsiyet } \\
\hline Kadın & $55(44,4)$ & $14(66,7)$ & $41(39,8)$ & & & \\
\hline Erkek & $69(55,6)$ & $7(33,3)$ & $62(60,2)$ & 1,25 & $0,84-1,86$ & 0,272 \\
\hline HT & $99(79,8)$ & $14(66,7)$ & $85(82,5)$ & 1,09 & $0,65-1,81$ & 0,755 \\
\hline Kardiyak hast & $76(61,3)$ & $8(38,1)$ & $68(66,0)$ & 1,63 & $1,08-2,45$ & $0,020 *$ \\
\hline DM & $41(33,1)$ & $5(23,8)$ & $36(35,0)$ & 1,10 & $0,73-1,64$ & 0,662 \\
\hline SVH & $27(21,8)$ & $3(14,3)$ & $24(23,3)$ & 1,64 & $1,04-2,60$ & $0,035^{*}$ \\
\hline Kanser & $25(20,2)$ & $1(4,8)$ & $24(23,3)$ & 1,95 & $1,22-3,12$ & $0,025^{*}$ \\
\hline КОАН & $22(17,7)$ & $2(9,5)$ & $20(19,4)$ & 1,71 & $1,04-2,81$ & $0,033^{*}$ \\
\hline Renal hast. & $17(13,7)$ & $1(4,8)$ & $16(15,5)$ & 1,24 & $0,73-2,13$ & 0,426 \\
\hline Tiroid hast. & $10(8,1)$ & $3(14,3)$ & $7(6,8)$ & 0,71 & $0,33-1,54$ & 0,388 \\
\hline Kollojen doku hast. & $4(3,2)$ & $1(4,8)$ & $3(2,9)$ & 0,67 & $0,21-2,12$ & 0,498 \\
\hline Karaciğer hast. & $3(2,4)$ & - & $3(2,9)$ & 1,05 & $0,33-3,32$ & 0,933 \\
\hline
\end{tabular}

Tablo 3. Hastaların aldıkları tedavilerin dağılımı

\begin{tabular}{|c|c|c|c|c|c|c|}
\hline \multirow[b]{2}{*}{ Değişkenler } & \multirow{2}{*}{$\begin{array}{c}\begin{array}{c}\text { Total } \\
\text { population } \\
n=124\end{array} \\
\end{array}$} & \multicolumn{2}{|c|}{ Survival } & \multicolumn{3}{|c|}{ Univariable Regression } \\
\hline & & $\begin{array}{c}\text { Sağ } \\
n=21\end{array}$ & $\begin{array}{l}\text { Exitus } \\
n=103\end{array}$ & HR & $95 \% \mathrm{Cl}$ & $p$ \\
\hline AML & $70(56,5)$ & $5(23,8)$ & $65(63,1)$ & 1,07 & $0,71-1,58$ & 0,776 \\
\hline \multicolumn{7}{|l|}{ Tipi } \\
\hline MDS MLD & $26(21,0)$ & $7(33,3)$ & $19(18,4)$ & ref & & \\
\hline MDS EB-1 & $63(50,8)$ & $11(52,4)$ & $52(50,5)$ & 1,68 & $0,99-2,84$ & 0,054 \\
\hline MDS EB-2 & $35(28,2)$ & $3(14,3)$ & $32(31,1)$ & 2,35 & $1,32-4,18$ & $0,004 *$ \\
\hline Eritropetin ted. & $24(19,4)$ & $4(19,0)$ & $20(19,4)$ & 0,74 & $0,45-1,20$ & 0,22 \\
\hline \multicolumn{7}{|l|}{ Hipometile ted. } \\
\hline Azasitidin & $69(55,6)$ & $10(47,6)$ & $59(57,3)$ & 0,69 & $0,17-2,86$ & 0,611 \\
\hline Desitabin & $53(42,7)$ & $11(52,4)$ & $42(40,8)$ & 0,77 & $0,18-3,21$ & 0,724 \\
\hline Imid ted. & $6(4,8)$ & - & $6(5,8)$ & 1,36 & $0,59-3,10$ & 0,469 \\
\hline $\begin{array}{l}\text { Immünsüpresif } \\
\text { ted. }\end{array}$ & $11(8,9)$ & $3(14,3)$ & $8(7,8)$ & 0,50 & $0,24-1,04$ & 0,063 \\
\hline IPSS skor & $1(0,5-3)$ & $1(0,5-2)$ & $1(0,5-3)$ & 1,77 & $1,30-2,40$ & $<0,001^{*}$ \\
\hline Düşük & $30(24,2)$ & $9(42,9)$ & $21(20,4)$ & ref & & \\
\hline Orta 1 & $59(47,6)$ & $10(47,6)$ & $49(47,6)$ & 1,80 & $1,08-3,02$ & $0,025^{*}$ \\
\hline Orta 2 & $35(28,2)$ & $2(9,5)$ & $33(32,0)$ & 2,82 & $1,61-4,93$ & $<0,001^{*}$ \\
\hline R-IPSS skor & $4,5(3,5-8,5)$ & $4(3,5-6)$ & $5(3,5-8,5)$ & 1,53 & $1,28-1,84$ & $<0,001 *$ \\
\hline Orta & $64(51,6)$ & $16(76,2)$ & $48(46,6)$ & ref & & \\
\hline Yüksek & $47(37,9)$ & $5(23,8)$ & $42(40,8)$ & 1,88 & $1,24-2,86$ & $0,003^{*}$ \\
\hline Çok yüksek & $13(10,5)$ & - & $13(12,6)$ & 4,19 & $2,21-7,96$ & $<0,001^{*}$ \\
\hline
\end{tabular}


Hastaların \%5,6'sında normosellüler, \%83,1'inde hipersellüler ve \%11,3'ünde hiposellüler saptandı ve kemik iliği sellülerite ortalaması $62,2 \pm 19,8$ olarak belirlendi. Sitogenetik risk olarak iyi grupta olan hastaların (-y, del $(11 q)$, del ( $5 q)$, del (12p), del (20 q)), oranı \%93,6 idi. Hemoglobin düzeylerinde azalama mortalite ile anlamlı ilişki gösterdi. Diğer klinik bulgular mortalite ile anlamlı ilişki göstermedi (Tablo 4).

Tablo 4. Hastaların klinik özellikleri

\begin{tabular}{|c|c|c|c|c|c|c|}
\hline \multirow[b]{2}{*}{ Değişkenler } & \multirow{2}{*}{$\begin{array}{c}\text { Total } \\
\text { population } \\
n=124\end{array}$} & \multicolumn{2}{|c|}{ Survival } & \multicolumn{3}{|c|}{ Univariable Regression } \\
\hline & & $\begin{array}{c}\text { Sağ } \\
n=21\end{array}$ & Exitus $n=103$ & HR & $95 \% \mathrm{Cl}$ & p \\
\hline \multicolumn{7}{|l|}{ Kemik_iliği } \\
\hline normosellüler & $7(5,6)$ & $1(4,8)$ & $6(5,8)$ & ref & & \\
\hline hipersellüler & $103(83,1)$ & $16(76,2)$ & $87(84,5)$ & 0,46 & $0,16-1,29$ & 0,461 \\
\hline hiposellüler & $14(11,3)$ & $4(19,0)$ & $10(9,7)$ & 0,76 & $0,33-1,76$ & 0,524 \\
\hline K.İ. sellülerite & $62,2 \pm 19,8$ & $64,3 \pm 20,6$ & $61,7 \pm 19,7$ & 1,05 & $0,99-1,11$ & 0,775 \\
\hline kiblast & $\begin{array}{c}6 \\
(1-18)\end{array}$ & $\begin{array}{c}6 \\
(1-18)\end{array}$ & $\begin{array}{c}6 \\
(1-18)\end{array}$ & 1,05 & $0,99-1,10$ & 0,069 \\
\hline hgb & $8,3 \pm 1,5$ & $8,5 \pm 1,5$ & $8,2 \pm 1,5$ & 0,86 & $0,76-0,98$ & $0,019 *$ \\
\hline plt & $\begin{array}{c}75,5 \\
(1-343)\end{array}$ & $\begin{array}{c}69 \\
(7-272)\end{array}$ & $\begin{array}{c}77 \\
(1-343)\end{array}$ & 0,99 & $0,99-1,00$ & 0,634 \\
\hline neutro & $\begin{array}{c}1595 \\
(130-17000)\end{array}$ & $\begin{array}{c}1800 \\
(300-8800)\end{array}$ & $\begin{array}{c}1590 \\
(130-17000)\end{array}$ & 1,00 & $0,99-1,05$ & 0,958 \\
\hline wbc & $\begin{array}{c}3700 \\
(800-25000)\end{array}$ & $\begin{array}{c}3800 \\
(1240-10000)\end{array}$ & $\begin{array}{c}3700 \\
(800-25000)\end{array}$ & 1,00 & $0,98-1,03$ & 0,569 \\
\hline lynphocyte & $\begin{array}{c}1450 \\
(270-6600)\end{array}$ & $\begin{array}{c}1800 \\
(500-3200)\end{array}$ & $\begin{array}{c}1400 \\
(270-6600)\end{array}$ & 1,00 & $0,98-1,04$ & 0,906 \\
\hline monosit & $\begin{array}{c}400 \\
(10-3900)\end{array}$ & $\begin{array}{c}350 \\
(20-2000)\end{array}$ & $\begin{array}{c}400 \\
(10-3900)\end{array}$ & 1,00 & $0,99-1,02$ & 0,104 \\
\hline
\end{tabular}

Mortaliteyi öngören bağımsız prediktörler yaş (HR:1,03; $p=0,022)$, kardiyak hastalık (HR:1,60; $p=0,026), \mathrm{KOAH}$ ( $r=1,78 ; p=0,027)$, yüksek R-IPSS skoru (HR: 2,10; $p=0,001$ ) ve çok yüksek R-IPSS skoru (HR:3,17; $p=0,001$ ) olarak saptandı (Tablo 5). Buna göre; yaşın 1 yıl artması 1,03 kat mortalite riskini arttırdığı saptandı. Sahip olunan her bir kronik hastalık diğerlerinden bağımsız olarak mortalite riski hesaplandı. Kardiyak hastalığı olanlar olmayanlara kıyasla 1,60 kat mortalite riskine sahipti. KOAH olanlar olmayanlara kıyasla 1,78 kat mortalite riskini sahipti. R-IPSS skoru yüksek olanlar orta olanlara kıyasla 2,10 kat mortalite riskine sahipti, çok yüksek olanlar orta olanlara kıyasla 3,17 kat mortalite riskine sahipti.

Tablo 5. Mortaliteyi öngören bağımsız risk faktörleri

\begin{tabular}{lccc}
\hline \multirow{2}{*}{ Variables } & \multicolumn{3}{c}{ Multivariable Regression } \\
\cline { 2 - 4 } & HR & $\mathbf{9 5 \%} \mathbf{C l}$ & $\mathbf{p}$ \\
\hline Yaş & 1,03 & $1,01-1,05$ & $022^{*}$ \\
Kardiak hast. & 1,60 & $1,06-2,41$ & $0,026^{*}$ \\
KOAH & 1,78 & $1,07-2,96$ & $0,027^{*}$ \\
R-IPSS skor & ref & \\
$\quad$ int & 2,10 & & $0,001^{*}$ \\
high & 3,17 & $1,37-3,28$ & $0,001^{*}$ \\
\hline
\end{tabular}

R-IPSS skoru orta olan hastalarda 1 yıllık sağ kalım oranı \%52,3, 3 yıllık sağ kalım oranı \%20,4 ve 5 yıllık sağ kalım oranı \%18,2 olarak saptandı. R-IPSS skoru yüksek olan hastalarda 1 yıllık sağ kalım oranı \%25,8, 3 yıllık sağ kalım oranı \%9,4 ve 5 yıllık sağ kalım oranı \%7 olarak saptandı. R-IPSS skoru çok yüksek olan hastalarda 1 yıllık sağ kalım oranı \%7,7 olarak saptandı, hastaların tamamı 3 yıldan önce exitus olduğu belirlendi (Şekil 2). 


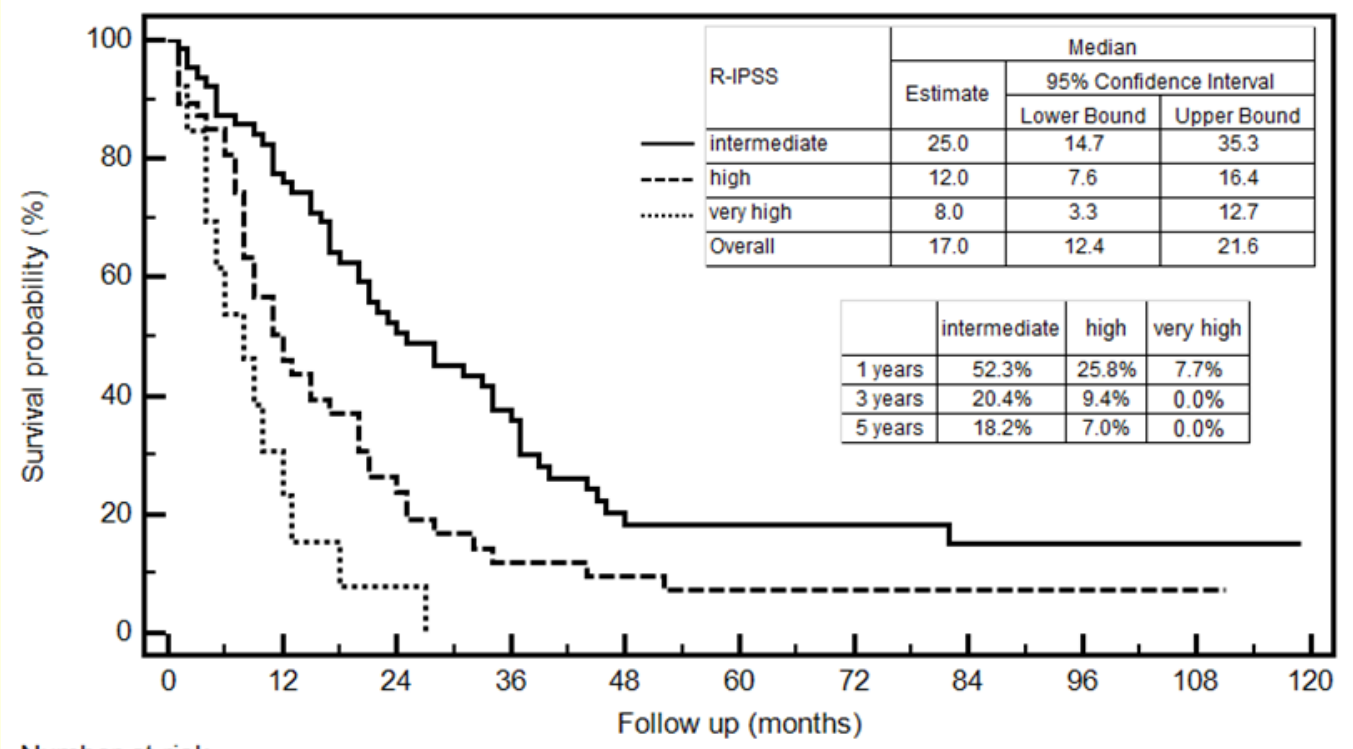

Number at risk

Group intermediate

\begin{tabular}{|c|c|c|c|c|c|c|c|c|c|}
\hline \multirow{2}{*}{\multicolumn{10}{|c|}{ Group: high }} \\
\hline & & & & & & & & & \\
\hline 47 & 21 & 10 & 5 & 4 & 3 & 3 & 2 & 2 & 2 \\
\hline Group: very high & & & & & & & & & \\
\hline 13 & 3 & 1 & 0 & 0 & 0 & 0 & 0 & 0 & 0 \\
\hline
\end{tabular}

Şekil 2. R-IPSS skorlarına göre hastaların sağkalım grafiği

\section{TARTIŞMA}

Kronik hastalıkların yüksek riskli MDS'li hastaların sağ kalımı üzerine etkisini değerlendirmek üzere geriye dönük bu çalışma planlandı. Kanserli hastalarda eşlik eden kronik hastalıkların ciddiyeti derecesi ile sağ kalım süresi arasındaki negatif ilişkiyi gösteren geniş çaplı birçok çalışma mevcuttur. MDS’li hastalarda prognositik değerlendirme üzerine yapılan çalışmalarda en anlamlı ilişki IPSS ve R-IPSS olarak tespit edilerek güncel kılavuzlarda yerini almıştır. Ancak hem IPSS hem de R-IPSS değerlendirmesinde yaş ve komorbiditeler yer almamaktadır. Ileri yaş ve kronik hastalıkların varlığı hastaların hayatta kalma sürelerini belirgin şekilde değiştirmektedir ${ }^{12,13}$.

Çalışmamızda ortalama yaşı 67 olarak saptanan yüksek riske sahip MDS hastalarının tamamı orta, yüksek ve çok yüksek riske sahip hastalardan oluşmaktaydı. Buna göre; yaşın 1 yıl artması 1,03 kat mortalite riskini arttırdığı saptandı. R-IPSS skoru orta olan hastalarda 1 yıllık sağ kalım oranı \%52,3, R-IPSS skoru yüksek olan hastalarda 1 yıllık sağ kalım oranı \%25,8, R-IPSS skoru çok yüksek olan hastalarda 1 yıllık sağ kalım oranı \%7,7 olarak saptandı (Şekil 2). IPSS'in hasta yaşına göre sağ kalım hesaplamasına olanak sağladığı kabul edilmelidir. Beklendiği gibi çalışmamızda hem ileri yaş hem de yüksek IPSS ve R-IPSS'in kötü sağ kalım ile ilişkili olduğunu bulduk. Bulgularımızın literatür ile uyumlu olduğu gözlendi. ${ }^{14,15}$

Çalışmamızda eşlik eden kronik hastalıklara bakıldığında en sık HT, DM, kardiyak hastalık, KOAH saptandı. Bu sonuçlar bizim için şaşırtıcı olmadı, çünkü hastalarımızın ortalama yaşı 67 idi ve HT, DM ve kardiyak hastalık bu yaş grubunda daha yüksek oranda gözlenmektedir. Tiroid hastalığı, karaciğer parenkim hastalığı, kanser ve kollajen doku hastalığı oranı toplumda beklenen sıklıkta izlendi ${ }^{16}$. Mortalite üzerine etkisine baktığımızda kardiyak hastalık, SVH, kanser ve KOAH mortalite riskini arttıran olası risk faktörleri olarak saptandı (Tablo 2). Kardiyak hastalığı olanlar olmayanlara kıyasla 1,60 kat mortalite riskine sahipti. KOAH olanlar olmayanlara kıyasla 1,78 kat mortalite riskini sahipti. Yakın zamanda yapılan birkaç çalışmada özellikle konjestif kalp yetmezliği ve KOAH olanlar hastalarda daha düşük sağ kalım öngeren yaşlı popülâsyona dayalı bir araştırma yapılmıştır ${ }^{17}$. Daha önceki çalışmalar konjestif kalp yetmezliği, pulmoner ve karaciğer yetmezliği, enfeksiyonlar, kanama ve solid tümörlerin MDS'deki lösemik olmayan ölümlerin ana nedenleri olduğunu göstermiştir. Mortaliteyi öngören bağımsız prediktörler yaş (HR:1,03; $p=0,022)$, kardiyak hastalık (HR:1,60; $p=0,026)$, KOAH ( $r=1,78 ; p=0,027)$, yüksek R-IPSS skoru (HR: 2,$10 ; p=0,001)$ ve çok yüksek R-IPSS skoru 
(HR:3,17; $p=0,001$ ) olarak saptandı (Tablo 5). Bu çalışmada komorbiditelerin sağ kalım konusunda MDS'de önemli bir ek risk faktörü olduğunu ve bulgularımızın literatür ile paralellik gösterdiğini saptadık ${ }^{13,18,19}$.

Çalışmamızın en büyük kısıtıılığı geriye dönük olması ve arşiv bilgilerinin doğruluğuna dayanmasıdır. Bir diğer kısıtlılığımız MDS ile ilişkili olmayan diğer ölüm nedenlerinin net olarak ayırt edilememiş. Ancak Yüksek riskli hastaların çalışmaya alınmış olması nedeni ile tüm hastaların aynı hastalık özellikleri taşıması yanlılığımızı engellemektedir. Sonuç olarak bu çalışma eşlik eden komorbiditelerin yüksek riskli MDS'li hastaların sağ kalımı üzerinde önemli bir etkiye sahip olduğunu ve komorbidite değerlendirmesinin yeni prognostik skorlamaların bir parçası olması gerektiğini göstermektedir. Bu nedenle komorbiditeler MDS'deki risk değerlendirmesinde ve bu hastaların genel tedavi planında bir mortalite risk faktörü olarak düşünülmelidir. Bu çalışma Mersin bölgesinde yüksek riskli MDS hastaları ile yapılmış ilk çalışma olup, bu bölgede özellikle kronik hastalığa sahip hastaların yönetiminde ve tedavisinde sağlayacağı katkı nedeni ile büyük öneme sahip olduğunu düşünmekteyiz. Aynı zamanda ülkemizde diğer merkezlerin katılımı ile sağlancak çok merkezli prospektif randomize kontrollü çalışmalar ile bu önemin daha iyi ortaya konabileceğini düşünmekteyiz.

\section{Kaynaklar}

1. Rollison DE., et al. 2008. Epidemiology of myelodysplastic syndromes and chronic myeloproliferative disorders in the United States, 2001-2004, using data from the NAACCR and SEER programs', Blood 112: 45-52.

2. Ma X., et al. Myelodysplastic syndromes: incidence and survival in the United States. Cancer 2007;109(8):1536.

3. Tricot $\mathrm{G}$, et al. Prognostic factors in the myelodysplastic syndromes: importance of initial data on peripheral blood counts, bone marrow cytology, trephine biopsy and chromosomal analysis. Br J Haematol 1985;60(1):19.

4. Jacobs RH, et al. Prognostic implications of morphology and karyotype in primary myelodysplastic syndromes. JD. Blood 1986;67(6):1765.

5. Greenberg P,. et al. International scoring system for evaluating prognosis in myelodysplastic syndromes. J. Blood 1997;89(6):2079.

6. Greenberg PL, at al. Revised international prognostic scoring system for myelodysplastic syndromes. Blood 2012;120(12):2454. Epub 2012 Jun 27.

7. Sperr WR, et al. Comorbidity as prognostic variable in MDS: comparative evaluation of the $\mathrm{HCT}-\mathrm{Cl}$ and $\mathrm{CCl}$ in a core dataset of 419 patients of the Austrian MDS Study Group. Ann Oncol 2010;21(1):114. Epub 2009 Jul 15.

8. Sanz GF, et al. T Two regression models and a scoring system. for predicting survival and planning treatment in myelodysplastic syndromes. A multivariate analysis of prognostic factors in 370 patients. Blood 1989; 74: 395-408

9. Malcovati L, et al. Prognostic factors and life expectancy in myelodysplastic syndromes classified according to WHO criteria: a basis for clinical decision making. J Clin Oncol 2005; 23: 7594-7603.

10. Sorror ML, et al. Comorbidity and disease status based risk stratification of outcomes among patients with acute myeloid leukemia or myelodysplasia receiving allogeneic hematopoietic cell transplantation. J Clin Oncol 2007; 25: 4246-4254.

11. Arber DA et al. The 2016 revision to the World Health Organization classification of myeloid neoplasms and acute leukemia. Blood 2016 May 19;127(20):2391 405.

12. Breccia $\mathrm{M}$, et al. Evaluation of comorbidities at diagnosis predicts outcome in myelodysplastic syndrome patients. Leuk Res 2011;35(2):159.

13. Della Porta MG, et al. Risk stratification based on both disease status and extra-hematologic comorbidities in patients with myelodysplastic syndrome. Haematologica 2011;96(3):441. Epub 2010 Dec 6.

14. Naqvi $\mathrm{K}$, et al. Association of comorbidities with overall survival in myelodysplastic syndrome: development of a prognostic model. J Clin Oncol 2011;29(16):2240. Epub 2011 May 2.

15. Etienne $\mathrm{A}$, et al. Comorbidity is an independent predictor of complete remission in elderly patients receiving induction chemotherapy for acute myeloid leukemia. Cancer 2007; 109: 1376-1383.

16. Pfeilstocker $\mathrm{M}$, et al: Myelodysplastic syndromes, aging, and age: Correlations, common mechanisms, and clinical implications. Leuk Lymphoma 48:1900-1909, 2007

17. Wang $R$, et al: Comorbidities and survival in a large cohort of patients with newly diagnosed myelodysplastic syndromes. Leuk. Res 33:1594-1598, 2009

18. Boogaerts MA, Verhoef GEG, Demutynk $\mathrm{H}$. Treatment and prognostic factors in myelodysplasic syndromes. Baillie' res Clin Haematol 1996; 9: 161-183.

19. Tefferi A, Vardiman JW. Myelodysplastic syndromes N Engl J Med 2009;361:1872-85. 